\title{
Efeito da estreptozotocina sobre os perfis glicêmico e lipídico e o estresse oxidativo em hamsters
}

\author{
Effect of streptozotocin on the glycemic and lipid \\ profiles and oxidative stress in hamsters
}

Maísa Silva', Wanderson Geraldo de Lima ${ }^{1,3}$, Marcelo Eustáquio Silva ${ }^{1,2}$, Maria Lucia Pedrosa ${ }^{1,3}$

${ }^{1}$ Núcleo de Pesquisas em Ciências Biológicas, Programa de Pósgraduação em Ciências Biológicas, Universidade Federal de Ouro Preto (UFOP), Ouro Preto, MG, Brasil 2 Departamento de Alimentos, UFOP, Ouro Preto, MG, Brasil ${ }^{3}$ Departamento de Ciências Biológicas, UFOP, Ouro Preto, MG, Brasil
Correspondência para: Maísa Silva

Universidade Federal de Ouro Preto, Campus Morro do Cruzeiro, Departamento de Ciências Biológicas, Bauxita

35400-000 - Ouro Preto, MG, Brasil maisasilv@yahoo.com.br

Recebido em 6/Jul/2010 Aceito em 16/Dez/2010

\section{RESUMO}

Objetivo: Este estudo avaliou os efeitos da estreptozotocina nos perfis glicêmico e lipídico e marcadores de estresse oxidativo em hamsteres. Materiais e métodos: Hamsteres machos Golden Syrian foram divididos em dois grupos: grupo diabético (D), que recebeu uma única injeção de estreptozotocina (STZ - $50 \mathrm{mg} / \mathrm{kg}$ ), e grupo controle (C), que recebeu injeção de tampão citrato. Os animais foram eutanasiados após 10 dias de experimento e o sangue, o fígado e rins foram coletados. Resultados: 0 grupo diabético apresentou níveis maiores de glicose, triacilgliceróis e colesterol séricos e maior concentração de substâncias reativas ao ácido tiobarbitúrico (TBARs) no fígado e nos rins. Também apresentou significativo aumento da concentração de glutationa no fígado e menores atividades da paraoxonase e do superóxido dismutase. Conclusão: Hamsteres fornecem um bom modelo para o diabetes melito do tipo le estresse oxidativo, similar ao da síndrome humana, e poderão ser adequados para a análise de compostos antidiabéticos. Arq Bras Endocrinol Metab. 2011;55(1):46-53

\section{Descritores}

Hamsteres; estreptozotocina; estresse oxidativo; antioxidantes

\begin{abstract}
Objective: This study evaluated the effects of streptozotocin on glycemic and lipid profiles and oxidative stress status in hamsters. Materials and methods: Male Golden Syrian hamsters were divided in diabetic group (D) which received a streptozotocin single injection (STZ - 50 mg/kg), and control group $(\mathrm{C})$ which received a single injection of the vehicle citrate buffer. Animals were euthanized after 10 days of experiment and blood, liver and kidneys were collected. Results: The diabetic group had higher levels of glucose, triacylglycerols and cholesterol in serum and thiobarbituric acid reactive substances (TBARS) concentration increased in the liver and kidneys. Diabetes induced a significant increase in glutathione concentration in the liver and decreased paraoxonase and superoxide dismutase activities. Conclusion: Hamsters provide a novel animal model for diabetes mellitus and oxidative stress, similar to the human syndrome, which may be suitable for the testing of antidiabetic compounds. Arq Bras Endocrinol Metab. 2011;55(1):46-53
\end{abstract}

Keywords

Hamsters; streptozotocin; oxidative stress; antioxidants

\section{INTRODUÇÃO}

$\mathrm{O}$ termo diabetes melito (DM) é uma desordem metabólica de múltiplas etiologias caracterizadas por hiperglicemia crônica com distúrbios no metabolismo de carboidratos, lipídios e proteínas, como resultado do defeito na secreção de insulina ou em sua ação ou am- bos (1). Há mais de 250 milhões de pessoas em todo o mundo com diabetes e estima-se que a cada 5 segundos surja um novo caso (2). O diabetes pode gerar complicações como retinopatias, nefropatias, neuropatias e distúrbios endócrinos. O papel do estresse oxidativo nessas complicações tem sido alvo de muito interesse $(3,4)$. 
O estresse oxidativo é um estado de desequilíbrio entre a produção de espécies reativas de oxigênio (ROS) e a capacidade antioxidante endógena. A geração aumentada de ROS no diabetes pode ser devida à auto-oxidação da glicose, à formação de produtos finais de glicação avançada (AGEs), à via dos polióis e também às mudanças no conteúdo e atividade no sistema de defesas antioxidantes no tecido (5). ROS causam, in vitro, danos à via de sinalização da insulina (6), diminuição da translocação dos transportadores de glicose (GLUT-4) nos adipócitos (7) e redução da internalização da insulina nas células endoteliais (8). Em adição, a oxidação de lipídios e de proteínas está associada com o desenvolvimento das complicações do diabetes (5).

Modelos animais com diabetes, que apresentem o status redox similar ao humano, serão úteis para analisarmos possíveis mecanismos que estejam envolvidos na relação diabetes e estresse oxidativo. $\mathrm{O}$ diabetes experimental pode ser induzido por fármacos, manipulação cirúrgica ou genética em várias espécies de animais. A maioria dos experimentos é realizada em roedores, embora alguns estudos sejam realizados em animais maiores. $\mathrm{O}$ modelo murino é o mais usado em decorrência da disponibilidade de mais de 200 linhagens bem caracterizadas e da habilidade de deletar ou superexpressar genes específicos por meio da tecnologia dos nocaute e transgênicos (9).

A estreptozotocina é uma glicosamina-nitrosureia comumente usada para produzir o diabetes. A droga é captada pelas células pancreáticas que contêm transportadores de glicose GLUT-2, então, células produtoras de insulina que não expressam esse transportador são resistentes à estreptozotocina (STZ) (10). Mecanismos são propostos para a citotoxicidade produzida pela STZ. A alcalinização do DNA celular e subsequente ativação da poli-ADP ribose sintetase causam depleção rápida $\mathrm{e}$ letal de NAD nas células pancreáticas, com subsequente redução no nível de ATP e posterior inibição da síntese e secreção da insulina $(11,12)$. Por outro lado, evidências indicam que os radicais livres podem ter um papel essencial no efeito diabetogênico da STZ (13). Hamsteres desenvolvem diabetes quando tratados com estreptozotocina (14), porém não existem trabalhos na literatura que avaliem vários produtos do estresse oxidativo e defesas antioxidantes em hamsteres diabéticos.

O estresse oxidativo pode ser avaliado por meio de atividade de enzimas envolvidas no balanço redox da célula, que incluem a superóxido dismutase, catalase, glutationa peroxidase e glutationa redutase, as quais convertem radicais superóxido em peróxidos ou peróxidos em água e oxigênio. A conversão de peróxido de hidrogênio pela glutationa peroxidase ocorre concomitante com a oxidação da glutationa reduzida $(\mathrm{GSH})$ para a forma oxidada (GSSG). O diabetes pode alterar a atividade dessas enzimas em vários tecidos (15). Compostos que podem ser modificados pela ação de radicais livres, como lipídios, proteínas e grupos sulfidrilas, são também usados como medidas indiretas do estresse oxidativo. $\mathrm{O}$ principal objetivo deste trabalho foi avaliar o estresse oxidativo em hamsteres com diabetes induzido por STZ.

\section{MATERIAIS E MÉTODOS}

\section{Animais utilizados}

Foram usados 14 Hamsteres Syrian Golden, machos, de 90 dias de idade, divididos em dois grupos, com 7 hamsteres cada. O manuseio dos animais foi realizado em concordância com os princípios éticos para manipulação de animais de experimentação (Colégio Brasileiro de Experimentação Animal) (16) e os procedimentos com os animais foram aprovados pelo Comitê de Ética em Pesquisa da Universidade Federal de Ouro Preto. Os grupos receberam dieta comercial (Labina-Purina) e água à vontade.

\section{Estabelecimento do diabetes melito experimental}

$\mathrm{O}$ diabetes melito foi induzido pela administração intraperitoneal de $50 \mathrm{mg} / \mathrm{kg}$ de estreptozotocina (17). O grupo controle recebeu uma injeção de tampão citrato, 0,01 M, pH 4,5, para que o mesmo estresse fosse provocado. Foram considerados diabéticos os hamsteres que após três dias da administração de STZ apresentaram perda de peso corporal e níveis de glicemia maiores ou iguais a $250 \mathrm{mg} / \mathrm{dL}$, em determinações com glicosímetro digital ACCU-CHEK (Roche).

\section{Eutanásia e preparação das amostras}

Os animais foram mortos no décimo dia de experimento, após anestesia, por sangria total pelo plexo braquial. Amostras de sangue foram coletadas e centrifugadas em tubos de 1,5 mL para a determinação de componentes séricos. O fígado e os rins foram removidos, pesados e estocados em nitrogênio líquido para análises bioquímicas.

\section{Análises bioquímicas séricas}

A concentração de glicose e frutosamina e a atividade da amilase foram determinadas utilizando kits Labtest 
(Labtest, Lagoa Santa, MG, Brasil), n 84,97 e 25, respectivamente. A concentração de proteínas totais séricas e albumina foi medida utilizando kits Labtest 99 e 19, respectivamente. Os níveis de triacilgliceróis e colesterol total foram dosados enzimaticamente usando o kit Labtest, cat 59 e 60, utilizando glicerol ou colesterol como padrão, respectivamente.

\section{Avaliações histopatológicas}

Fragmentos não excedentes a $4 \mathrm{~mm}$ de diâmetro de pâncreas, fixados em solução de formol a $10 \%$, foram desidratados, diafanizados e embebidos em parafina. Após inclusão, os fragmentos foram seccionados em micrótomo rotativo para a obtenção de slides de parafina de aproximadamente $4 \mu \mathrm{m}$ e posterior fixação em lâminas de vidro previamente limpas e desengorduradas. As lâminas foram coradas pela técnica histológica de rotina da Hematoxilina \& Eosina, para visualização das alterações histológicas. As análises morfométricas digitais para a determinação da área das ilhotas pancreáticas foram realizadas no microscópio óptico Leica DM5000 associado ao software de análise Leica Qwin plus.

\section{Atividade de enzimas e compostos antioxidantes}

A atividade de paraoxonase (PON) no soro (atividade arilesterásica) foi determinada de acordo com Beltowski e cols. (18). A atividade arilesterásica foi calculada utilizando o coeficiente de extinção molar do fenilacetato, que é de $1310 \mathrm{~L} \cdot \mathrm{mol}^{-1} \cdot \mathrm{cm}^{-1}$. Os resultados foram expressos em unidades por $\mathrm{mL}$, em que $\mathrm{l} U$ de arilesterase hidrolisa $1 \mathrm{mmol}$ de fenilacetato por minuto. A atividade enzimática da paraoxonase no soro (atividade sobre o paraoxon) foi calculada utilizando o coeficiente de extinção molar do substrato, que é de 18.290 L. $\mathrm{mol}^{-1} \cdot \mathrm{cm}^{-1}$. Os resultados foram expressos por unidades por $\mathrm{mL}$, em que $1 \mathrm{U}$ de enzima hidrolisa $1 \mathrm{mmol}$ de paraoxon por minuto (18).

Para determinar a atividade da superóxido dismutase (SOD), usamos o kit Fluka 19160 (Steinheim, Germany). Esse ensaio usa a xantina e a xantina oxidase para gerar radicais superóxidos que reagem com 2-(4-iodofenil)-3-(4-nitrofenol)-5-pfeniltetrazoliumclorido para produzir formazan, um composto que absorve luz a $450 \mathrm{~nm}$. A inibição da produção do cromógeno é proporcional à atividade da SOD presente na amostra.

Os grupos sulfidrilas totais foram estimados usando o reagente de Ellman's de acordo com Sedlak and Lindsay (19). Brevemente, $40 \mu \mathrm{L}$ de plasma foram misturados com $150 \mu \mathrm{L}$ de $0,2 \mathrm{M}$ de tampão Tris $\mathrm{HCl}$ ( $\mathrm{pH} 8,2$ ) contendo $20 \mathrm{mM}$ EDTA e com $50 \mu \mathrm{L}$ de 5,5 ditiobis-(2-ácido nitrobenzoico) (DTNB, $10 \mathrm{mM}$ solução em metanol). Então, $800 \mu \mathrm{L}$ de metanol foram adicionados, a amostra foi centrifugada a 10.000 g por 15 minutos e a absorbância do sobrenadante foi determinada a $412 \mathrm{~nm}$. A absorbância da amostra branco (sem DTNB) e reagente branco (sem plasma) foi subtraída da concentração de sulfidrilas e calculada pela curva padrão preparada com concentração conhecida de cisteína.

A concentração de glutationa total (GSH e GSSH) em homogenatos de fígado foi determinada usando o kit Sigma CS0260 (EUA). Esse kit utiliza um método cinético para mensurar os níveis de glutationa, por meio da redução do DTNB (ácido 5,5'-Ditio-bis-(2-nitrobenzoico) a TNB, que é determinado espectrofotometricamente a $412 \mathrm{~nm}$. Foi utilizado um padrão de glutationa reduzida Sigma G4251.

\section{Análise de peroxidação lipídica}

Amostras de fígado de todos os hamsteres foram homogeneizadas com tampão Tris- $\mathrm{HCl} 0,1 \mathrm{M} \mathrm{pH} \mathrm{7,4} \mathrm{(1:10).}$ $\mathrm{O}$ conteúdo de lipídios peroxidados foi determinado de acordo com Buege e Aust (20). Brevemente, 250 $\mu \mathrm{L}$ de tricloroacético (TCA) a $28 \%$ foram adicionados a $500 \mu \mathrm{L}$ de amostra, $250 \mu \mathrm{L}$ de ácido tiobarbitúrico (TBA) (1\% em ácido acético $1: 1)$ e $125 \mu \mathrm{L}$ de hidroxibutiltolueno (BHT) (5 mM dissolvido em etanol) e incubados a $95^{\circ} \mathrm{C}$ por 15 minutos. Subsequentemente, a mistura foi centrifugada a 10.000 g por 15 minutos. A absorbância do sobrenadante foi feita a $535 \mathrm{~nm}$ usando espectrofotômetro. O conteúdo de lipídio peroxidado foi calculado usando o coeficiente de extinção molar do complexo TBA-MDA 1,56 x $10^{5}$ mol-1.cm- 1 .

\section{Análise da oxidação proteica}

Amostras de fígado e rins de todos os hamsteres foram homogeneizadas em tampão fosfato $50 \mathrm{mM}, \mathrm{pH}: 6,7$ ( $1: 10)$. O conteúdo de grupos carbonilas nesses homogenatos foi determinado pelo método de Levine modificado (21). Primeiramente, $0,5 \mathrm{~mL}$ de amostra foi precipitado usando $0,5 \mathrm{~mL}$ de TCA $10 \%$ e centrifugado a $5.000 \mathrm{~g}$ por 10 minutos, descartando-se o sobrenadante. Foram adicionados a esse precipitado $10 \mathrm{mM}$ de difenil-hidrazina (DNPH) HCl2M e incubados à temperatura ambiente por 30 minutos. Durante a incubação, as amostras foram vigorosamente misturadas a cada 15 minutos. Depois da incubação, $0,5 \mathrm{~mL}$ de TCA $10 \%$ foi adicionado e as proteínas foram precipitadas e centrifugadas a $5.000 \mathrm{~g}$ por 10 minutos. Depois de descar- 
tar o sobrenadante, o precipitado foi lavado duas vezes com uma mistura de acetato de etila e etanol (1:1), centrifugado e o sobrenadante descartado. O precipitado foi dissolvido em SDS 6\% e centrifugado a $10.000 \mathrm{~g}$ por 10 minutos. O sobrenadante foi lido a $370 \mathrm{~nm}$ contra $\mathrm{HCl} 2 \mathrm{M}$. Os níveis de proteínas carboniladas foram expressos em nanomoles por $\mathrm{mL}$ usando a coeficiente de extinção molar do DNPH $\left(22000 \mathrm{~mol}^{-1} \cdot \mathrm{cm}^{-1}\right)$.

\section{Análises estatísticas}

Os dados foram analisados pelo teste de normalidade Kolmogorov-Smirnov. Todos os dados seguiram uma distribuição normal e foram analisados pelo teste de $t$ de Student. Os dados foram expressos como média \pm desvio-padrão. Em todos os testes, foram considerados significantes os resultados com valores de $p \leq 0,05$.

\section{RESULTADOS}

Avaliação do efeito da injeção de estreptozotocina sobre o perfil glicêmico, perfil lipídico e função hepática de hamsteres

Inicialmente, analisamos os níveis de glicose e os níveis de frutosamina. Ao analisar os dados da concentração de glicose dos hamsteres que receberam a injeção de estreptozotocina, na tabela 1 , podemos notar que ela está aumentada cerca de 7 vezes. A concentração de frutosamina não foi influenciada pelo tratamento com STZ $(\mathrm{p}>0,05)$. A porcentagem total de área pancreática ocupada pelas ilhotas foi de $8,23 \%$ para o grupo C, significativamente maior que a porcentagem da área ocupada pelas ilhotas pancreáticas de $2,98 \%$ nos animais D (Figuras l e 2). As concentrações de proteínas totais e albumina sérica não apresentaram diferença significativa entre os grupos. A análise estatística do peso dos fígados não demonstrou diferenças entre os grupos, mas os pesos dos rins apresentaram-se 1,5 vez aumentado nos hamsteres diabéticos (Tabela 1 ).

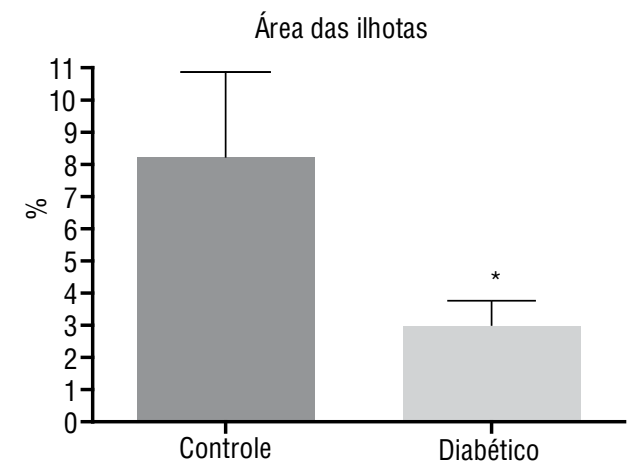

Os valores são apresentados como média e desvio-padrão $(n=7)$. Os dados foram analisados pelo teste de normalidade Kolmogorov-Smirnov. Todos os dados seguiram uma distribuição normal e foram analisados por teste de $t$. Diferenças estatísticas são mostradas * ${ }^{*} p<0,05$.

Figura 2. Área das ilhotas pancreáticas dos hamsteres controles e diabéticos

Tabela 1. Perfil glicêmico, indicadores bioquímicos da função hepática e peso corporal, do fígado e dos rins em hamsteres

\begin{tabular}{lccc}
\hline & Controle & Diabético & $\begin{array}{c}\text { Valores } \\
\text { de p }\end{array}$ \\
\hline Glicose $\mathrm{mmol} / \mathrm{L}$ & $2,51 \pm 0,92$ & $18,55 \pm 4,3^{*}$ & 0,004 \\
Frutosamina $\mu \mathrm{mol} / \mathrm{L}$ & $232,76 \pm 110,43$ & $227,83 \pm 47,76$ & 0,920 \\
Albumina $\mu \mathrm{mol} / \mathrm{L}$ & $265,36 \pm 25,33$ & $285,86 \pm 30,19$ & 0,299 \\
Proteínas totais séricas g/L & $61,64 \pm 4,16$ & $68,7 \pm 35,94$ & 0,721 \\
Peso corporal final g & $130,88 \pm 12,99$ & $113,55 \pm 17,92^{*}$ & 0,026 \\
Peso do fígado g & $3,38 \pm 0,45$ & $3,24 \pm 0,97$ & 0,756 \\
Peso dos rins g & $0,82 \pm 0,06$ & $1,28 \pm 0,14^{*}$ & 0,0003 \\
\hline
\end{tabular}

Os valores são apresentados como média e desvio-padrão $(\mathrm{n}=7)$. Os dados foram analisados pelo teste de normalidade Kolmogorov-Smirnov. Todos os dados seguiram uma distribuição normal e foram analisados por teste de $t$. Diferenças estatísticas são mostradas por ${ }^{*}, p<0,05$.
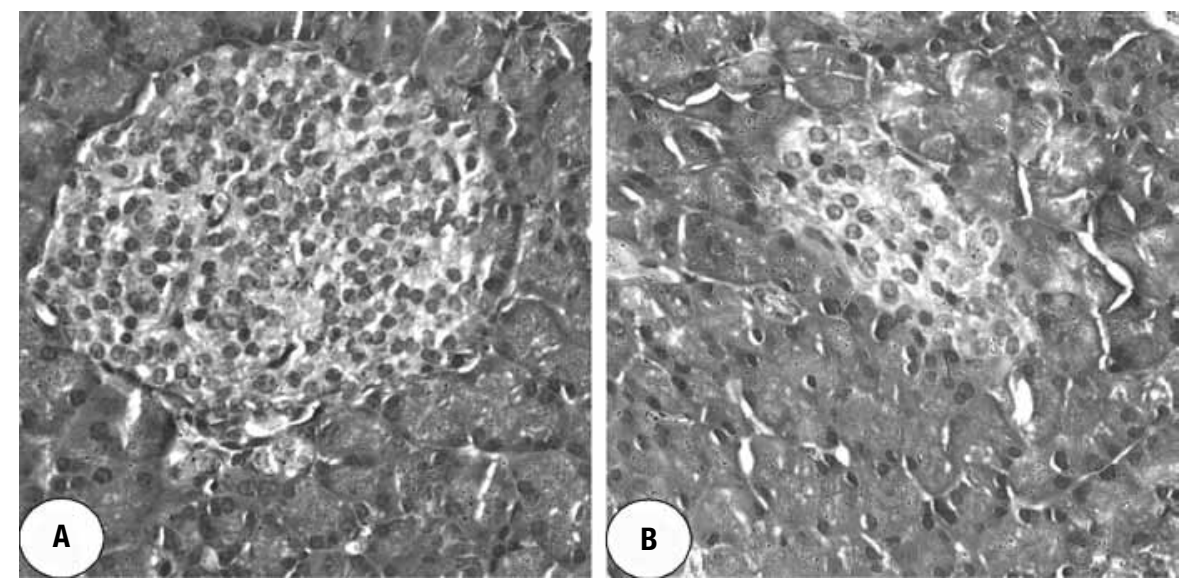

Figura 1. Fotomicrografias histológicas de cortes pancreáticos. (A) Grupo controle. (B) Grupo diabético. Note a diminuição do tamanho das ilhotas pancreáticas comparado ao grupo controle. Coloração: Hematoxilina \& Eosina. Barra $=50 \mu \mathrm{M}$. 
A análise estatística dos dados revelou que a concentração de triacilgliceróis apresentava-se 2,7 vezes aumentada nos hamsteres diabéticos, como mostrado na tabela 2. A concentração de colesterol total foi 4,5 vezes aumentada pelo diabetes. Verificamos que o tratamento com STZ em hamsteres também promoveu alterações no perfil lipídico, similares às encontradas para humanos. As atividades séricas da PON sobre os substratos fenilacetato e o paraoxon apresentaram-se $44 \%$ e $31 \%$ diminuídas, respectivamente.

Tabela 2. Perfil lipídico e atividade da paraoxonase em hamsteres

\begin{tabular}{llll}
\hline & \multicolumn{1}{c}{ Controle } & \multicolumn{1}{c}{ Diabético } & $\begin{array}{c}\text { Valores } \\
\text { de } \mathbf{p}\end{array}$ \\
\hline Triacilgliceróis $\mathrm{mmol} / \mathrm{L}$ & $1,03 \pm 0,13$ & $2,87 \pm 0,8^{\star}$ & 0,018 \\
Colesterol $\mathrm{mmol} / \mathrm{L}$ & $6,28 \pm 2,82$ & $28,44 \pm 11,55^{\star}$ & 0,029 \\
PON paraoxon U/mL & $93,73 \pm 27,27$ & $54,33 \pm 13,08^{\star}$ & 0,010 \\
PON fenilacetato U/mL & $23,7 \pm 3,82$ & $16,18 \pm 3,37^{\star}$ & 0,011 \\
\hline
\end{tabular}

PON: paraoxonase. Os valores são apresentados como média e desvio-padrão $(n=7)$. Os dados foram analisados pelo teste de normalidade Kolmogorov-Smirnov. Todos os dados seguiram uma distribuição normal e foram analisados por teste de $t$. Diferenças estatísticas são mostradas por $^{*}, p<0,05$

\section{Análise dos efeitos do diabetes sobre as defesas antioxidantes e marcadores do estresse oxidativo}

O status antioxidante foi mensurado pela dosagem da concentração de $\mathrm{SH}$ total, atividade da superóxido dismutase e da concentração de glutationa total no fígado e nos rins. A tabela 3 mostra que não há diferenças na concentração de grupos sulfidrilas totais no soro entre os grupos. A concentração de glutationa total no fígado apresentou-se 8,2 vezes aumentada nos hamsteres diabéticos. Já a concentração de glutationa total nos rins não foi modificada. Notamos também que a atividade da enzima superóxido dismutase no soro apresentou um aumento de 2,5 vezes no grupo diabético comparado ao controle.

A análise de nossos dados não revelou diferença significativa para a concentração de proteína carbonilada no fígado e nos rins nos grupos estudados (Tabela 3 ). Porém, a concentração de TBARS no fígado e rim dos hamsteres diabéticos revelou-se 2,6 vezes e 2,4 vezes aumentada, respectivamente, pelo teste de $t$.

\section{DISCUSSÃO}

Animais com diabetes induzido por substâncias químicas têm sido usados para estudar o diabetes dependente de insulina. A indução de diabetes em hamsteres utilizando STZ pode ser conseguida utilizando doses
Tabela 3. Status oxidativo em hamsteres

\begin{tabular}{|c|c|c|c|}
\hline & Controle & Diabético & $\begin{array}{l}\text { Valores } \\
\text { de } p\end{array}$ \\
\hline SH total $\mu \mathrm{mol} / \mathrm{L}$ & $283,38 \pm 64,86$ & $268,22 \pm 19,46$ & 0,710 \\
\hline $\begin{array}{l}\text { Glutationa no fígado } \\
\text { nmoles/mL }\end{array}$ & $1,13 \pm 0,34$ & $9,28 \pm 4,33^{*}$ & 0,036 \\
\hline $\begin{array}{l}\text { Glutationa nos rins } \\
\text { nmoles/mL }\end{array}$ & $6,91 \pm 3,98$ & $5,87 \pm 4,57$ & 0,623 \\
\hline Superóxido dismutase \% & $90,55 \pm 7,33$ & $71,2 \pm 13,19^{*}$ & 0,0243 \\
\hline $\begin{array}{l}\text { Proteína carbonilada fígado } \\
\mathrm{U} / \mathrm{mL}\end{array}$ & $33,37 \pm 18,43$ & $23,27 \pm 16,01$ & 0,356 \\
\hline $\begin{array}{l}\text { Proteína carbonilada rim } \\
\mathrm{U} / \mathrm{mL}\end{array}$ & $13,84 \pm 4,84$ & $14,21 \pm 4,84$ & 0,911 \\
\hline TBARS fígado nmoles/mL & $1,08 \pm 0,43$ & $2,87 \pm 1,71^{*}$ & 0,035 \\
\hline TBARS rim nmoles/mL & $1,22 \pm 0,79$ & $2,87 \pm 1,210^{*}$ & 0,0424 \\
\hline
\end{tabular}

SH: sulfidrilas totais, TBARS: substâncias reativas ao ácido tiobarbitúrico. Os valores são apresentados como média e desvio-padrão $(\mathrm{n}=7)$. Os dados foram analisados pelo teste de normalidade Kolmogorov-Smirnov. Todos os dados seguiram uma distribuição normal e foram analisados por teste de $t$. Diferenças estatísticas são mostradas * $, p<0,05$.

múltiplas de droga ou em uma dose única $(17,22)$. Em nosso trabalho aplicamos uma dose única de $50 \mathrm{mg} /$ $\mathrm{kg}$ de STZ e observamos um aumento significativo da concentração de glicose sérica desde o terceiro dia após a aplicação. Os animais permaneceram com a glicose significativamente aumentada até serem eutanasiados no décimo dia. Possivelmente, em decorrência do curto tempo de experimento, a concentração de frutosamina dos hamsteres diabéticos não foi alterada, pois essa reflete a concentração de proteínas que foram glicadas há aproximadamente três semanas e, portanto, no curto período do experimento não foi possível detectar alterações nesse parâmetro. A diminuição da área ocupada pelas ilhotas pancreáticas dos hamsteres do grupo D confirma esse quadro, sugerindo que a dose de STZ aplicada foi capaz de provocar diabetes tipo 1 nos animais. Hipercolesterolemia em animais tratados com estreptozotocina resulta da absorção intestinal e da síntese aumentadas de colesterol (23). As lipoproteínas de ratos diabéticos são oxidadas e demonstram citotoxicidade, um aspecto que pode ser prevenido pela insulina ou tratamento antioxidante. Trabalhos mostram que o metabolismo de lipídios de hamsteres é influenciado pelo diabetes, aumentando a concentração de triacilgliceróis e colesterol $(24,25)$, corroborando com dados deste trabalho.

Bell e cols. (26) demonstraram que hamsteres que receberam a mesma concentração de STZ que os animais do presente trabalho apresentaram tumores hepáticos. Assim, avaliamos um possível dano hepático por meio de marcadores séricos e não observamos nenhuma 
mudança nas concentrações de proteínas e albumina. Isso pode indicar que alterações em parâmetros bioquímicos observados não foram devidas às lesões hepáticas e sim próprias do diabetes.

Estresse oxidativo aumentado e mudanças na capacidade antioxidante são observados em diabetes melito clínico e experimental e podem contribuir para complicações dessa doença (5). Corroborando com isso, nossos dados mostram uma diminuição de enzimas antioxidantes e um aumento de produtos do estresse oxidativo.

Ocorre aumento do estresse oxidativo e da peroxidação lipídica em macrófagos e em lipoproteínas na presença de hiperglicemia e hipertrigliceridemia (27). A enzima PON associada com a HDL protege a LDL e a HDL contra a oxidação e também elimina lipídios oxidados das células (28). A atividade sérica da PON se encontra diminuída no diabetes melito (29), o que também foi verificado em nosso trabalho.

Esta enzima também pode atuar de forma suicida neste processo e então ser usada para prevenir a peroxidação de HDL. Essa teoria é apoiada pela observação da diminuição da atividade da PON quando exposta a peróxidos de lipídios. A atividade diminuída da PON 1 pode ser relacionada à glicação do HDL e consequente perda de função, que ocorre no diabetes. Foi verificado por Hedrick e cols. (30) uma diminuição de $65 \%$ na atividade de PON em HDL glicado e uma redução de $40 \%$ na atividade enzimática, quando a PON purificada é exposta diretamente à glicação. Não existem trabalhos na literatura que verifiquem a atividade dessa enzima em hamsteres diabéticos e isso se torna mais importante devido ao fato de esse animal apresentar o metabolismo de lipoproteínas tão semelhante ao humano.

O radical superóxido, o primeiro produto da redução da molécula de oxigênio, tem um elétron desemparelhado em sua órbita externa e isso resulta em uma fonte importante de hidroperóxidos e de radicais livres tóxicos. Uma célula normal tem a habilidade de detoxificar radicais superóxido por meio de enzimas como a superóxido dismutase. A SOD, junto com outras enzimas como a catalase, glutationa redutase, ajuda a manter a concentração de glutationa e NADPH necessário para a ótima função dos mecanismos de defesas antioxidantes. Vários trabalhos com animais tratados com STZ mostram uma diminuição da atividade de SOD. Mohan and Das (31) demonstraram uma diminuição da atividade de SOD no plasma de ratos diabéticos; porém, trabalhos demonstrando os efeitos causados pelo diabetes sobre a atividade de SOD em hamsteres são escassos. Observamos também uma atividade diminuída em nossos hamsteres, corroborando com os trabalhos em outros modelos experimentais.

Os dados das enzimas superóxido dismutase, glutationa peroxidase ou redutase e catalase muitas vezes são controversos. Como verificado para diabetes em alguns modelos experimentais ou diferentes tecidos, elas podem se encontrar aumentadas ou diminuídas. $\mathrm{O}$ aumento de suas expressões e, consequentemente, de suas atividades pode ser devido a um mecanismo regulado em nível transcricional (32). Sob condições fisiológicas normais, a transcrição do fator Nrf2 é inibida pela proteína repressora Keapl localizada no citoplasma das células (33). A proteína Keapl contém resíduos conservados de cisteína, os quais desempenham um papel crítico na manutenção do Nrf2 no citoplasma. Entretanto, um aumento na produção de EROS no organismo promove no citoplasma a dissociação desse complexo, fazendo com que o Nrf2 fique ativado, sendo transportado para o núcleo $(34,35)$. No núcleo das células, esse fator de transcrição se liga a elementos de resposta a antioxidantes (ARE) na região promotora dos genes que transcrevem enzimas antioxidantes endógenas. A ativação Nrf2-ARE induz a produção da superóxido dismutase, catalase, glutationa peroxidase, glutationa reduzida, peroxiredoxinas, nicotinamida adenina dinucleotídeo fosfato (NADPH): quinona oxidoredutases (NQOs) e hemoxigenases. Juntas, essas enzimas e peptídeos representam um potente mecanismo antioxidante de defesa. Uma vez restabelecido o balanço redox da célula, o Nrf2 é dissociado do núcleo pelo Keapl e subsequentemente transportado para o citoplasma, onde é ubiquitinado e degradado (32). Essa pode ser uma explicação para nosso resultado de concentração de glutationa total no fígado, que se apresentou aumentado talvez por esse mecanismo de defesa do organismo ativado pelo aumento de oxidantes.

Hidroperóxidos têm um efeito tóxico nas células, diretamente ou por meio de grande degradação de radicais hidroxil tóxicos. Eles também podem reagir com metais de transição e formar aldeídos, como o malondialdeído, que causa danos às membranas celulares. O aumento de espécies reativas ao ácido tiobarbitúrico, que é uma evidência indireta da intensa produção de radicais livres, é visto em vários trabalhos com ratos tratados com estreptozotocina e aloxana $(36,37)$. Em hamsteres, Takatori e cols. (38) analisaram a concentração de malondialdeído e 4-HNE, outro aldeído forma- 
do da peroxidação lipídica, e verificaram também um aumento nas suas concentrações em animais que receberam uma dose de STZ, o que corrobora com nossos resultados.

As principais mudanças estruturais em proteínas podem ser caracterizadas pelas dosagens de proteína carbonilada (PCO), perda de grupos tióis e produtos de oxidação proteica avançada (AOPP). O uso da proteína carbonilada como marcador possui algumas vantagens em relação a outros marcadores, como sua formação relativamente rápida, grande estabilidade e longo tempo de vida. Esses compostos carbonilados podem contribuir para as complicações diabéticas. Considerando que em nossos animais está ocorrendo um aumento do estresse oxidativo, um baixo nível de danos a proteínas pode ser interpretado como um resultado da eficiência alta do sistema de antioxidantes, o que pode estar sendo promovido pela estimulação via $\mathrm{Nrf}-2$, causada pelo diabetes.

A ausência de mudanças significativas na concentração de proteínas carboniladas e grupos sulfidrilas, combinada com efeito significativo do diabetes sobre os lipídios peroxidados, sugere que os substratos bioquímicos diferentes possuem suscetibilidade diferente ao estresse produzido pelo diabetes. Isso corrobora com trabalhos realizados em outros roedores, que não observaram mudanças em todos os produtos gerados pelo estresse oxidativo (39).

Os mecanismos pelos quais o estresse oxidativo aumentado está envolvido nas complicações diabéticas são parcialmente conhecidos. Muitas pesquisas com resultados positivos em outros roedores não apresentaram os mesmos resultados satisfatórios em humanos diabéticos. Este trabalho mostrou o hamster como um bom modelo experimental para ajudar na elucidação de mecanismos e identificar terapias adicionais ao tratamento do diabetes.

Agradecimentos: este estudo foi financiado pela Fundação de Amparo à Pesquisa de Minas Gerais (Fapemig, Minas Gerais, Brasil $n^{\circ}$ CDS-APQ 01126-08) e Conselho Nacional de Desenvolvimento Científico e Tecnológico $(\mathrm{CNPq}$, Brasil; no. 475823/2007-9). Agradecemos ao Professor Rinaldo Cardoso dos Santos pelas sugestões e revisão cuidadosa do manuscrito.

Declaração: os autores declaram não haver conflitos de interesse científico neste estudo.

\section{REFERENCES}

1. Conget I. [Diagnosis, classification and cathogenesis of diabetes mellitus]. Rev Esp Cardiol. 2002;55(5):528-35.
2. Type 2 diabetes in children and adolescents. American Diabetes Association. Diabetes Care. 2000;23(3):381-9.

3. Ceriello A. Oxidative stress and glycemic regulation. Metabolism. 2000;49(2 Suppl 1):27-9.

4. Reis JS, Veloso CA, Mattos RT, Purish S, Nogueira-Machado JA. [Oxidative stress: a review on metabolic signaling in type 1 diabetes]. Arq Bras Endocrinol Metabol. 2008;52(7):1096-105.

5. Baynes JW. Role of oxidative stress in development of complications in diabetes. Diabetes 1991;40(4):405-12.

6. Najib S, Sanchez-Margalet V. Homocysteine thiolactone inhibits insulin signaling, and glutathione has a protective effect. J Mol Endocrinol. 2001;27(1):85-91.

7. Rudich A,Tirosh A, Potashnik R, Hemi R, Kanety H, Bashan N. Prolonged oxidative stress impairs insulin-induced GLUT4 translocation in 3T3-L1 adipocytes. Diabetes. 1998;47(10):1562-9.

8. Bertelsen M, Anggard EE, Carrier MJ. Oxidative stress impairs insulin internalization in endothelial cells in vitro. Diabetologia. 2001;44(5):605-13.

9. Rees DA, Alcolado JC. Animal models of diabetes mellitus. Diabet Med. 2005;22(4):359-70.

10. Elsner M, Guldbakke B, Tiedge M, Munday R, Lenzen S. Relative importance of transport and alkylation for pancreatic beta-cell toxicity of streptozotocin. Diabetologia. 2000;43(12):1528-33.

11. Bennett RA, Pegg AE. Alkylation of DNA in rat tissues following administration of streptozotocin. Cancer Res. 1981;41(7):2786-90.

12. Bolzan AD, Bianchi MS. Genotoxicity of streptozotocin. Mutat Res. 2002;512(2-3):121-34.

13. Takasu N, Komiya I, Asawa T, NagasawaY,YamadaT. Streptozocinand alloxan-induced $\mathrm{H} 2 \mathrm{O} 2$ generation and DNA fragmentation in pancreatic islets. $\mathrm{H} 2 \mathrm{O} 2$ as mediator for DNA fragmentation. Diabetes. 1991;40(9):1141-5.

14. Phares CK. Streptozotocin-induced diabetes in Syrian hamsters: new model of diabetes mellitus. Experientia. 1980;36(6):681-2.

15. Rauscher FM, Sanders RA, Watkins JB, III. Effects of new antioxidant compounds PNU-104067F and PNU-74389G on antioxidant defense in normal and diabetic rats. J Biochem MolToxicol. 2000;14(4):189-94.

16. Colégio Brasileiro de Experimentação Animal. Princípios éticos na experimentação animal do Colégio Brasileiro de Experimentação Animal. São Paulo: COBEA, 1991.

17. Simionescu M, Popov D, Sima A, Hasu M, Costache G, Faitar S, et al. Pathobiochemistry of combined diabetes and atherosclerosis studied on a novel animal model. The hyperlipemic-hyperglycemic hamster. Am J Pathol. 1996;148(3):997-1014.

18. Beltowski J,Wojcicka G, Jamroz A. Differential effect of 3-hydroxy-3-methylglutaryl coenzyme A reductase inhibitors on plasma paraoxonase 1 activity in the rat. Pol J Pharmacol. 2002;54(6):661-71.

19. Sedlak J, Lindsay RH. Estimation of total, protein-bound, and nonprotein sulfhydryl groups in tissue with Ellman's reagent. Anal Biochem. 1968;25(1):192-205.

20. Buege JA, Aust SD. Microsomal lipid peroxidation. Methods Enzymol. 1978;52:302-10.

21. Levine RL, Williams JA, Stadtman ER, Shacter E. Carbonyl assays for determination of oxidatively modified proteins. Methods Enzymol. 1994;233:346-57.

22. El-Swefy S, Schaefer EJ, Seman LJ, van DD, Sevanian A, Smith $D E$, et al. The effect of vitamin $E$, probucol, and lovastatin on oxidative status and aortic fatty lesions in hyperlipidemic-diabetic hamsters. Atherosclerosis. 2000;149(2):277-86.

23. Ebara T, Hirano T, Mamo JC, Sakamaki R, Furukawa S, Nagano S, et al. Hyperlipidemia in streptozocin-diabetic hamsters as a model for human insulin-deficient diabetes: comparison to streptozocin-diabetic rats. Metabolism. 1994;43(3):299-305.

24. Ebara T, Hirano T, Mamo JC, Sakamaki R, Furukawa S, Nagano S, et al. Hyperlipidemia in streptozocin-diabetic hamsters as a mo- 
del for human insulin-deficient diabetes: comparison to streptozocin-diabetic rats. Metabolism. 1994;43(3):299-305.

25. Mathe D. Dyslipidemia and diabetes: animal models. Diabete Metab. 1995;21(2):106-11.

26. Bell Jr RH, Hye RJ, Miyai K. Streptozotocin-induced liver tumors in the Syrian hamster. Carcinogenesis. 1984;5(10):1235-8.

27. Griendling KK, Alexander RW. Oxidative stress and cardiovascuIar disease. Circulation. 1997;96(10):3264-5.

28. Aviram M. Introduction to the serial review on paraoxonases, oxidative stress, and cardiovascular diseases. Free Radic Biol Med. 2004;37(9):1301-3.

29. Abbott CA, Mackness MI, Kumar S, Boulton AJ, Durrington PN. Serum paraoxonase activity, concentration, and phenotype distribution in diabetes mellitus and its relationship to serum lipids and lipoproteins. ArteriosclerThromb Vasc Biol. 1995;15(11):1812-8.

30. Hedrick CC, Hassan K, Hough GP, Yoo JH, Simzar S, Quinto CR, et al. Short-term feeding of atherogenic diet to mice results in reduction of HDL and paraoxonase that may be mediated by an immune mechanism. ArteriosclerThromb Vasc Biol. 2000;20(8):1946-52.

31. Mohan IK, Das UN. Effect of L-arginine-nitric oxide system on chemical-induced diabetes mellitus. Free Radic Biol Med. 1998;25(7):757-65.

32. KenslerTW, Wakabayashi N, Biswal S. Cell survival responses to environmental stresses via the Keap1-Nrf2-ARE pathway. Annu Rev Pharmacol Toxicol. 2007;47:89-116.
33. Itoh K, Wakabayashi N, Katoh $\mathrm{Y}$, Ishii T, O'Connor T, Yamamoto $M$. Keap1 regulates both cytoplasmic-nuclear shuttling and degradation of Nrf2 in response to electrophiles. Genes Cells. 2003;8(4):379-91.

34. Dahl EL, Mulcahy RT. Cell-type specific differences in glutamate cysteine ligase transcriptional regulation demonstrate independent subunit control. Toxicol Sci. 2001;61(2):265-72.

35. de Vries HE, Witte M, Hondius D, Rozemuller AJ, Drukarch B, Hoozemans J, et al. Nrf2-induced antioxidant protection: a promising target to counteract ROS-mediated damage in neurodegenerative disease? Free Radic Biol Med. 2008;45(10):1375-83.

36. Aragno M, Tamagno E, Gatto V, Brignardello E, Parola S, Danni O, et al. Dehydroepiandrosterone protects tissues of streptozotocin-treated rats against oxidative stress. Free Radic Biol Med. 1999;26(11-12):1467-74.

37. Jain SK. The neonatal erythrocyte and its oxidative susceptibility. Semin Hematol. 1989;26(4):286-300.

38. Takatori $A$, Ohta $E$, Inenaga $T$, Horiuchi $K$, Ishii $Y$, Itagaki $S$, et al. Protective effects of probucol treatment on pancreatic beta-cell function of SZ-induced diabetic APA hamsters. Exp Anim. 2003;52(4):317-27.

39. Hase M, Babazono T, Karibe S, Kinae N, Iwamoto Y. Renoprotective effects of tea catechin in streptozotocin- induced diabetic rats. Int Urol Nephrol. 2006;38(3-4):693-9. 